\title{
The Meaning of Words and Why They Matter During End-of-Life Conversations
}

\author{
Grace Cullen, DNP, FNP-BC, ACHPN, AOCNP, RN-BC
}

Effective communication during end-of-life is crucial for health care delivery,
but misinterpretation can influence how the quality of the care is rendered and perceived.

W hen I was a new palliative care nurse practitioner (NP), I remember my mentor telling me that communication in our field is equivalent to surgical procedures in general surgery. Conversations need to be handled with accuracy and precision, conducted in a timely fashion, and require skills that take practice to sharpen. Over the years, I learned that unlike surgery, we do not have control over how the procedure will flow. We approach patients with a blank canvas, open to receive messages that will be shared and reacted to accordingly. The ability to communicate effectively also requires compassion, which is a trait that tends to be inherent in humans and typically is not learned from textbooks but can be cultivated with training and application.

Among the barriers identified to effective communication are avoiding emotional issues and focusing on technical topics due in part to the fear of lengthy encounters, not allowing patients or families enough time to speak, and reframing instead of validating emotions. ${ }^{1}$ Many years later, I had the chance to help care for a patient whose story reminds me of how our choice of words and how our interpretation of what we are told can influence the way we care for patients and their families.

\section{CASE PRESENTATION}

Mr. P, aged 86 years, was admitted to a teaching hospital for pneumonia and heart failure exacerbation. He was treated with diuretics and antibiotics and discharged home on room air after 3 days. He returned to the hospital after 8 days, reporting labored breathing. He was found to be hypoxic, and a further workup revealed acute hypoxic respiratory failure that was likely from severe pulmonary hypertension and exacerbation of his heart failure. Left heart disease is a common cause of pulmonary hypertension, which can lead to right ventricular failure and increased mortality. ${ }^{2}$

After meeting with his pulmonologist and cardiologist, Mr. P elected for a do-notresuscitate code status and declined to be intubated. He also refused further diagnostics and life-prolonging treatments for his conditions, including a stress test, cardiac catheterization, and a right heart catheterization. He required bilevel positive airway pressure (BPAP) support at bedtime, which he also declined. He agreed to the use of supplemental oxygen through a nasal cannula and always needed 5 liters of oxygen.

Palliative care was consulted to assist with goals of care discussion. This visit took place during the COVID-19 pandemic, but Mr. P had tested negative for the COVID virus, so the palliative care NP was able to meet with Mr. P in person. He shared his understanding of the serious nature of his condition and the likelihood of a limited life expectancy without further diagnostics and possible lifeprolonging treatments. He said his goal was to go home and spend the remainder of his life with his wife. He had not been out of bed since his hospitalization except to transfer to a nearby chair with the help of his nurse due to exertional dyspnea and generalized weakness. Prior to his recent hospitalizations, he was independently ambulating and had no dyspnea when performing strenuous activities. Mr. P shared that his wife was aged in her 70s and was legally blind. He added that she did not require physical assistance, but he was unsure whether she could help him because they had not been in such a situation previously. They had a daughter who visited frequently and helped with driving them to doctors' appointments and shopping. Mr. P shared that he wanted to go home. After explaining the option of home hospice, Mr. P decided he wanted to receive hospice services at home and asked
Grace Cullen is a Nurse Practitioner at John D. Dingell Veterans Affairs Medical Center in Detroit, Michigan. Correspondence: Grace Cullen (grace.cullen@va.gov)

Fed Pract. 2021;38(11). Published online November 12. doi:10.12788/fp.0185 
palliative care NP to contact his daughter to let her know his wishes and to tell her more about how hospice can help with his care.

The palliative care NP met with Mr. P's nurse and shared the outcome of her visit. His nurse asked the palliative care NP whether she was familiar with his daughter. The nurse added that she wanted the palliative care NP to know that Mr. P's daughter was quite angry and upset with his doctors after being told about his prognosis. His doctors' notes also indicated that Mr. P wanted them to contact his daughter regarding his condition and plans for discharge, concluding that he deferred to his daughter for medical decision making.

As Mr. P's hospitalization took place during the COVID pandemic, a face-to-face meeting with his family was not possible. The NP spoke with Mr. P's daughter over the phone to relay his wishes and goals for his care. Mr. P's daughter cried at times during the conversation and asked whether his condition was really that serious. The NP allowed Mr. P's daughter to express her sadness and allowed for periods of silence during the conversation while his daughter gathered her composure. The NP reinforced the clinical information she had been provided by the medical team. Mr. P's daughter added that he was completely independent, not requiring supplemental oxygen and was otherwise healthy just a month prior. She also asked whether there was truly nothing else that could be done to prolong his life. The NP acknowledged her observations and explained how Mr. P's body and organs had not been able to bounce back from the recent insults to his overall physical condition.

After being told that Mr. P's options for treatment were limited not only by his advanced age and comorbidities, but also the limitations and goals for his care he had identified, his daughter supported her father's decision. The palliative care NP provided her information on how home hospice assists in her father's care at home, including symptom management, nursing visits, home equipment, family support, among others. Mr. P's daughter also said she would relay the information to her mother and call the palliative care NP if they had additional questions or concerns.

The outcome of her visit with Mr. P and his daughter were relayed by the palliative care NP to his acute health care team through an official response to the consultation request via his electronic health record. The palliative care NP also alerted the palliative care social worker to follow-up with Mr. P, his daughter, and his acute health care team to coordinate hospice services at the time of his discharge from the hospital.

Mr. P was discharged from the hospital with home hospice services after a few days. Three weeks later, Mr. P passed away peacefully on the in-patient unit of his home hospice agency as his physical care needs became too much for his family to provide at home a few days before his death. The palliative care social worker later shared with the NP that Mr. P's daughter shared her gratitude and satisfaction with the care he had received not only from palliative care, but also from everyone during his hospitalization.

\section{DISCUSSION}

Key themes found in end-of-life (EOL) communication with families and caregivers include highlighting clinical deterioration, involvement in decision making, continuation of high-quality care after cessation of aggressive measures, tailoring to individuals, clarity, honesty, and use of techniques in delivery. ${ }^{2}$ Some of the techniques identified were pacing, staging, and repetition. ${ }^{3}$ Other techniques that can be beneficial include allowing for time to express one's feelings, being comfortable with brief periods of silence, validating observations shared, among others. These themes were evident in the interactions that his health care team had with Mr. P and his daughter. With honesty and clarity, various members of the health care team repeatedly shared information regarding his clinical deterioration.

\section{Family Influence}

EOL decision-making roles within a family tend to originate from family interactional histories, familial roles as well as decisionmaking situations the family faces. ${ }^{4}$ The US medical and legal systems also recognize formal role assignments for surrogate decision makers. ${ }^{4}$ In the case of Mr. P, his advance directive (AD) identified his daughter as his surrogate decision maker. ADs are written statements made in advance by patients expressing their wishes and limitations for treatment as well as appointing surrogate 
decision makers when they become unable to decide for themselves in the future. ${ }^{5}$

During discussions about the goals for his care, Mr. P made his own medical decisions and elected to pursue a comfort-focused approach to care. His request for his health care team to reach out to his daughter was largely due to his need for assistance in explaining the complexity of his clinical condition to her and how hospice services would be helpful with his EOL care. Mr. P depended on his daughter to bring him to the hospital or to his doctors' appointments, and she had been a major source of support for him and his wife. Contrary to the belief of some of his health care practitioners, Mr. P was not deferring his medical decisions to his daughter but rather allowing for her participation as his health care partner.

Communication between nurses and patients has been found to be challenging to both parties. Nurses express difficulties in areas that include supporting patients and families after they have had a difficult conversation with their physicians and responding to patients and family members' emotions like anger. ${ }^{6}$ EOL care issues, such as family barriers to prognostic understanding, can interfere with psychosocial care. ${ }^{6}$ Families of patients approaching the EOL describe feeling mentally worn down and being unable to think straight, leading to feelings of being overwhelmed. ${ }^{7}$ They feel the need to be in a place where they can accept the content of difficult EOL conversations to be able to effectively engage. ${ }^{7}$

Studies have shown that family members of patients at the EOL experience stress, anxiety, fatigue and depression. ${ }^{8}$ Reactions that can be perceived as anger may not be so nor directed to the health care team. Questions raised regarding the accuracy of prognostication and treatment recommendations may not necessarily reflect concerns about the quality of care received but an exercise of advocacy in exploring other options on behalf of the patient. Allowing time for families to process the information received and react freely are necessary steps to facilitate reaching a place where they can acknowledge the information being relayed.

\section{Communication Skills Training}

Every member of the health care team should be equipped with the basic skills to have these conversations. The academic curricula for members of the health care team focuses on developing communication skills, but there has been a lack of content on palliative and EOL care. ${ }^{9}$

Due to time constraints and limited opportunities in the clinical setting, there has been an increasing use of simulation-based learning activities (SBLA) to enhance communication skills among nursing students. ${ }^{9}$ At this time, the impact of SBLA in enhancing communication competency is not fully known, but given the lack of clinical opportunities for students, this option is worth considering. ${ }^{9}$ When asked, nurses recognized the need for improved EOL communication education, training, and guidelines. ${ }^{10}$ They also felt that a multidisciplinary approach in EOL communication is beneficial. The inclusion of the End-of-Life Nursing Education Consortium (ELNEC) Core training in Bachelor of Science in Nursing programs have led to improved insight on palliative care and nurses' role in palliative care and hospice among nursing students. ${ }^{11}$

The Palliative Care and Hospice Education and Training Act of 2017 amended the Public Health Service Act to include improving EOL training for health care providers, including talking about death and dying. ${ }^{12}$ Even though the Liaison Committee of Medical Education asked medical schools to incorporate EOL care education in the medical school curricula, there is still a lack of developmentally appropriate and supervised EOL education in medical schools. ${ }^{12}$ Training on grief also has been lacking and less likely to be mandatory among medical students and residents: Workshops are mostly conducted before they can be applied in the clinical setting. ${ }^{13}$ Meanwhile, resources are available to assist physicians in EOL conversations with patient and families, such as the Serious Illness Conversation Guide, The Conversation Project, and Stanford's Letter Project. ${ }^{12}$

\section{CONCLUSIONS}

Palliative consultation is associated with an overall improvement in EOL care, communication, and support, according to families of deceased patients. ${ }^{14}$ It has also been shown to enhance patients' quality of life and mood, improve documentation of resuscitation preferences, and lead to less aggressive care at 
the EOL, including less chemotherapy. ${ }^{15}$ Integration of palliative care in the care of patients hospitalized with acute heart failure has been associated with improved quality of life, decreased symptom burden and depressive symptoms, and increased participation in advance care planning. ${ }^{16}$

The involvement of palliative care in the care of patients and their families at EOL enhances goals of care discussions that improve understanding for everyone involved. It helps provide consistency with the message being delivered by the rest of the health care team to patients and families regarding prognosis and recommendations. Palliative care can provide an alternative when all other aggressive measures are no longer helpful and allow for the continuation of care with a shift in focus from prolonging life to promoting its quality. Furthermore, palliative care involvement for care of patients with life-limiting illness also has been found to improve symptom control, decrease hospitalizations and health care costs, and even improve mortality. ${ }^{17}$

A multidisciplinary approach to palliative care EOL conversations is beneficial, but every member of the health care team should have the training, education, and skills to be ready to have these difficult conversations. These health care team members include physicians, advance practice clinicians, nurses, social workers, and chaplains, among others. Patients and families are likely to be in contact with different members of the health care team who should be able to carry out therapeutic conversations. Using validated tools and resources on communication techniques through evidence-based practice is helpful and should be encouraged. This provides a framework on how EOL conversations should be conducted in the clinical setting to augment the identified lack of training on EOL communication in schools. Repeated opportunities for its use over time will help improve the ability of clinicians to engage in effective EOL communication.

\section{Author disclosures}

The author reports no actual or potential conflicts of interest with regard to this article.

\section{Disclaimer}

The opinions expressed herein are those of the author and do not necessarily reflect those of Federal Practitioner, Frontline Medical Communications Inc., the US Government, or any of its agencies.

\section{References}

1. MacKenzie AR, Lasota M. Bringing life to death: the need for honest, compassionate, and effective end-of-life conversations. Am Soc Clin Oncol Educ Book. 2020;40:476-484. doi:10.1200/EDBK_279767

2. Krishnan U, Horn E. Pulmonary hypertension due to left heart disease (group 2 pulmonary hypertension) in adults. Accessed September 17, 2021. https://www.uptodate.com /contents/pulmonary-hypertension-due-to-left-heart -disease-group-2-pulmonary-hypertension-in-adults

3. Anderson RJ, Bloch S, Armstrong M, Stone PC, Low JT. Communication between healthcare professionals and relatives of patients approaching the end-of-life: a systematic review of qualitative evidence. Palliat Med. 2019;33(8):926941. doi:10.1177/0269216319852007

4. Trees AR, Ohs JE, Murray MC. Family communication about end-of-life decisions and the enactment of the decision-maker role. Behav Sci (Basel). 2017;7(2):36. doi: $10.3390 /$ bs7020036

5. Arruda LM, Abreu KPB, Santana LBC, Sales MVC. Variables that influence the medical decision regarding advance directives and their impact on end-oflife care. Einstein (Sao Paulo). 2019;18:eRW4852. doi:10.31744/einstein_journal/2020RW4852

6. Banerjee SC, Manna R, Coyle N, et al. The implementation and evaluation of a communication skills training program for oncology nurses. Transl Behav Med. 2017;7(3):615-623. doi:10.1007/s13142-017-0473-5

7. Mitchell S, Spry JL, Hill E, Coad J, Dale J, Plunkett A. Parental experiences of end of life care decision-making for children with life-limiting conditions in the paediatric intensive care unit: a qualitative interview study. BMJ Open. 2019;9(5):e028548. doi:10.1136/bmjopen-2018-028548

8. Laryionava K, Pfeil TA, Dietrich M, Reiter-Theil S, Hiddemann W, Winkler EC. The second patient? Family members of cancer patients and their role in endof-life decision making. BMC Palliat Care. 2018;17(1):29. doi:10.1186/s12904-018-0288-2

9. Smith MB, Macieira TGR, Bumbach MD, et al. The use of simulation to teach nursing students and clinicians palliative care and end-of-life communication: a systematic review. Am J Hosp Palliat Care. 2018;35(8):1140-1154. doi:10.1177/1049909118761386

10. Griffiths I. What are the challenges for nurses when providing end-of-life care in intensive care units? Br J Nurs. 2019;28(16):1047-1052. doi:10.12968/bjon.2019.28.16.1047

11. Li J, Smothers A, Fang W, Borland M. Undergraduate nursing students' perception of end-of-life care education placement in the nursing curriculum. J Hosp Palliat Nurs. 2019;21(5):E12-E18. doi:10.1097/NJH.0000000000000533

12. Sutherland R. Dying well-informed: the need for better clinical educationsurrounding facilitating end-of-life conversations. Yale J Biol Med. 2019;92(4):757-764.

13. Sikstrom L, Saikaly R, Ferguson G, Mosher PJ, Bonato $S$, Soklaridis S. Being there: a scoping review of grief support training in medical education. PLoS One. 2019;14(11):e0224325. doi:10.1371/journal.pone.0224325

14. Yefimova M, Aslakson RA, Yang L, et al. Palliative care and end-of-life outcomes following highrisk surgery. JAMA Surg. 2020;155(2):138-146. doi:10.1001/jamasurg.2019.5083

15. Temel JS, Greer JA, Muzikansky A, et al. Early palliative care for patients with metastatic non-smallcell lung cancer. N Engl J Med. 2010;363(8):733-42. doi:10.1056/NEJMoa1000678.

16. Sidebottom AC, Jorgenson A, Richards H, Kirven J, Sillah A. Inpatient palliative care for patients with acute heart failure: outcomes from a randomized trial. J Palliat Med. 2015;18(2):134-142. doi:org/10.1089/jpm.2014.0192

17. Diop MS, Rudolph JL, Zimmerman KM, Richter MA, Skarf LM. Palliative careinterventions for patients with heart failure: a systematic review and meta-analysis. J Palliat Med. 2017;20(1):84-92. doi:10.1089/jpm.2016.0330 